\title{
ESTADO NUTRICIONAL, CONOCIMIENTOS Y CONDUCTAS EN ESCOLARES DE KINDER Y PRIMER AÑO BÁSICO EN 3 ESCUELAS FOCALIZADAS POR OBESIDAD INFANTIL EN LA COMUNA DE VALPARAÍSO, CHILE
}

\author{
NUTRITIONAL STATUS, KNOWLEDGE AND NUTRITIONAL \\ BEHAVIOUR IN SCHOOL CHILDREN FROM KINDERGARTEN \\ AND FIRST GRADE FROM THREE SCHOOLS IDENTIFIED FOR \\ CHILD OBESITY IN THE ZONE OF VALPARAISO, CHILE
}

\author{
Mirta Crovetto M. (1), Nancy Zamorano F. (2), Angelina Medinelli S. (2) \\ (1) Universidad de Playa Ancha, Valparaíso, Chile \\ (2) Corporación Municipal de Salud, Valparaíso, Chile
}

\begin{abstract}
In 2008, under the National Plan for Health Promotion and Community Plan for the Promotion of Health, actions to address school obesity by intervening with the Global Strategy Against Obesity schools with the highest obesity prevalence focusing on kindergarten levels (school children between 5-6 years) and first grade (students between 6-7 years). The actions of the Community Plan for the Promotion of Health in selected schools of Valparaiso were evaluated. The objectives of this intervention were: 1) assess the nutritional status of children from the participating levels, 2) gather background information on knowledge and behaviors related to food, nutrition and lifestyle in school and 3) identify strengths and difficulties facing the implementation of health policies at local level. We performed a descriptive, non-experimental, non-random convenience sample which included 267 schools. Results: It was detected $18.8 \%$ obesity in the transition level (kindergarten and $27 \%$ in the first grade evaluated according to Technical Standards of the Ministry of Health of Chile based on 2006 WHO reference tables. In order to assess knowledge and behavior, we developed and applied the tools "Caritas" and "Healthier Snacks" observing 77\% and $87 \%$ and $90 \%$ and $64 \%$ of correct associations for knowledge and behaviors, respectively. Facilitators: cooperative work and valuation from education. Barriers: outdated actions altering school curriculum planning. Figures of malnutrition by excess and the difficulty to reverse this reality require programs to in identify nutritional knowledge and eating behaviors of the population.
\end{abstract}

Keywords: Obesity, kindergarten and first grade, health promotion, health policies.

Este trabajo fue recibido el 6 de Mayo de 2010 y aceptado para ser publicado el 5 de Julio de 2010.

\section{INTRODUCCIÓN}

En el marco de las políticas nacionales de salud de Chile, en 1998 se formuló el Plan Nacional de Promoción de la Salud (1) y en el 2000 se establecieron las condicionantes de la salud, estrategias y metas sanitarias a lograr para el año 2010 (2).Los Establecimientos Educacionales Promotores de la Salud (EEPS), definidos por el Ministerio de Salud (MINSAL) como centro de educación pre-escolar, básico y/o medio donde sus miembros realizan actividades que contribuyen a elevar el nivel de salud de la comunidad educativa (3), promueven la formación de generaciones futuras con conocimientos, habilidades, destrezas y el autocuidado de la salud, familia y comunidad. Los EEPS, abordan las condicionantes de la promoción de la salud; entre ellas, la alimentación, considerada prioritaria para enfrentar los problemas relacionados con la malnutrición por exceso, mejorar el estado nutricional y poder 
reconocer las variables que determinan las conductas y hábitos alimentarios de la comunidad para enfrentar la obesidad escolar (4), que ha tenido un incremento sostenido en este grupo en los últimos 15 años, constituye una de las principales preocupaciones en materia de salud, afectando a los países desarrollados y en vías de desarrollo (5).

En Chile, los niños que ingresan al sistema público de educación son los que presentan las tasas más altas de obesidad (6). En el año 2007, las cifras entregadas por la Junta Nacional de Auxilio Escolar y Becas (JUNAEB), dependiente del Ministerio de Educación, informó que el $21,8 \%$ de los escolares, presentaba obesidad y 22,4 $\%$ sobrepeso, indicando un alza respecto al año 2006, que era de un $21,7 \%$. En el año 2008, se observa un leve descenso de la obesidad, respecto al 2007, alcanzando a un $20,8 \%$ de los escolares que ingresan al primer año básico (7). En el año 2008, en la Estrategia Global contra la Obesidad (EGO) (8), se determinó como prioridad para el cumplimiento de las metas sanitarias intervenir las escuelas que presenten los más altos índices de obesidad, focalizando la acción en los escolares del nivel de kinder y en los alumnos de primer año básico, identificando a los que presentan obesidad para su derivación al Consultorio de Salud del sector, para el control y vigilancia de su estado nutricional.

En este contexto, en la comuna de Valparaíso, en el plan comunal de promoción (9) se realiza un acuerdo entre la Corporación Municipal de Valparaíso (CORMUVAL), VIDA CHILE y la Carrera de Nutrición y Dietética de la Universidad de Playa Ancha, para la coordinación intersectorial y de alianzas estratégicas con los Consultorios Padre Damián, Esperanza y Barón, para abordar la condicionante alimentación en tres, de las cuatro escuelas focalizadas por obesidad infantil; Cirujano Videla, Escuela Barón y Escuela Esperanza. Los objetivos de esta intervención fueron; 1) evaluar el estado nutricional de los alumnos de los niveles participantes;2) recopilar antecedentes sobre conocimientos y conductas asociadas a alimentación y nutrición y estilos de vida en los preescolares de transición mayor (kinder) y primer año básico, de padres y apoderados y de profesores y 3) identificar dificultades y fortalezas que enfrentan la implementación de las políticas en promoción de la salud a nivel local.

\section{METODOLOGÍA}

Se trata de un estudio descriptivo en preescolares de transición mayor y escolares de primer año básico, con un diseño no experimental, la muestra intencionada no aleatoria. Participaron todos los sujetos disponibles el día en que se realizó la evaluación y que se aplicaron los instrumentos. Se desarrolló el año 2008 entre mayo y diciembre, en las escuelas Cirujano Videla, Gaspar Cabrales y Esperanza de la comuna de Valparaíso, focalizadas por el alto índice de obesidad en el marco del Plan Comunal de Promoción de la Salud y de la EGO.

\section{DESCRIPCION DE LA MUESTRA}

Muestra intencionada no aleatoria, participaron todos los alumnos disponibles de transición mayor y primer año básico de las escuelas seleccionadas. El universo contempló a 290 escolares y la muestra quedó conformada por 267 escolares con la siguiente distribución; 101 escolares en kinder, (37.8\%) y 166 (62.2\%) en escolares de primer año básico. Según sexo y nivel escolar, la distribución fue de 42 niñas (41.6\%) y 59 varones (58.4\%) en kinder y, de 72 niñas (43.3\%) y 94 varones. (56.6\%) en primer año básico. El promedio de edad en el nivel de kinder fue de 5 años 4 meses, para ambos sexos y de 6 años 5 meses para mujeres y de 6 años 6 meses para hombres, en primer año básico.

\section{ESTADO NUTRICIONAL}

En las escuelas seleccionadas se realizó una evaluación de la condición nutricional de los escolares participantes. El peso y la estatura fueron determinados por estudiantes de 4to año de la Carrera de Nutrición y Dietética, Universidad de Playa Ancha supervisadas por los nutricionistas de la CORMUVAL y de los Consultorios. Se utilizó una balanza mecánica SECA con cartabón incorporado con una escala de precisión de 0,1 $\mathrm{kg}$ para el peso y $1 \mathrm{~mm}$ para la estatura. Las mediciones se realizaron durante la mañana en similar período de tiempo, en un intervalo de dos semanas. El peso y la talla se evaluaron con camiseta, ropa interior y calcetas. Para los menores de 6 años, el estado nutricional se determinó usando los parámetros antropométricos propuestos en las Normas Técnicas del Ministerio de Salud de Chile (MINSAL) en base a la referencia de la OMS 2006 (10); peso para la edad (P/E); talla para la edad (T/E) y relación peso/talla ( $\mathrm{P} / \mathrm{T})$. Los puntos de corte para clasificar el estado nutricional fueron los siguientes; menor $(<)$ a 2 desviaciones estándar (DE); desnutrido; entre -1 y -2DE ; riesgo de desnutrir>; entre -1 y 1DE; normal; entre 1 y2 DE; riesgo de obesidad; mayor a 2DE; obesidad. Para los mayores de 6 años, se utilizó el Indice de Masa Corporal (IMC) $(\mathrm{kg} / \mathrm{m} 2)$ (11). Se comparó el IMC por edad (en meses) y sexo con la referencia CDC/NCHS 2000. Los puntos de corte para clasificar el estado nutricional fueron los siguientes; bajo peso IMC; < percentil 10; peso normal; IMC percentil $\geq 10$ - $<85$; sobrepeso IMC percentil 85-94; obeso IMC percentil; $\geq 95$. 


\section{CONOCIMIENTOS Y CONDUCTAS EN ALI- MENTACIÓN}

Para evaluar los conocimientos y conductas en alimentación de los escolares se elaboraron dos instrumentos de medición. Los instrumentos se construyeron en base a parámetros de la escala hedónica facial $(12,13)$ y a la capacidad de pensamiento abstracto según nivel escolar y edad, considerando las indicaciones dadas por grupo de expertos consultados para su elaboración, análisis y validación. El instrumento para diagnosticar conocimientos se llamó "Caritas" y el instrumento para diagnosticar conductas se denominó "Conociendo mis hábitos alimentarios".Ambas mediciones se aplicaron en actividades individuales o grupales realizadas al interior de las salas de clase en forma continua.

\section{CONOCIMIENTOS EN ALIMENTACIÓN. CARITAS}

Se determinó la elaboración de un conjunto de ilustraciones (imágenes) de alimentos saludables y no saludables, asociadas a una figura, representada por una carita feliz y sana y a otra figura representada por una carita triste y enferma, según condición del alimento (tabla 1). El método consistió en asociar láminas de

\section{TABLA 1}

\section{Asociaciones de alimentos saludables y no saludables para el cuerpo}

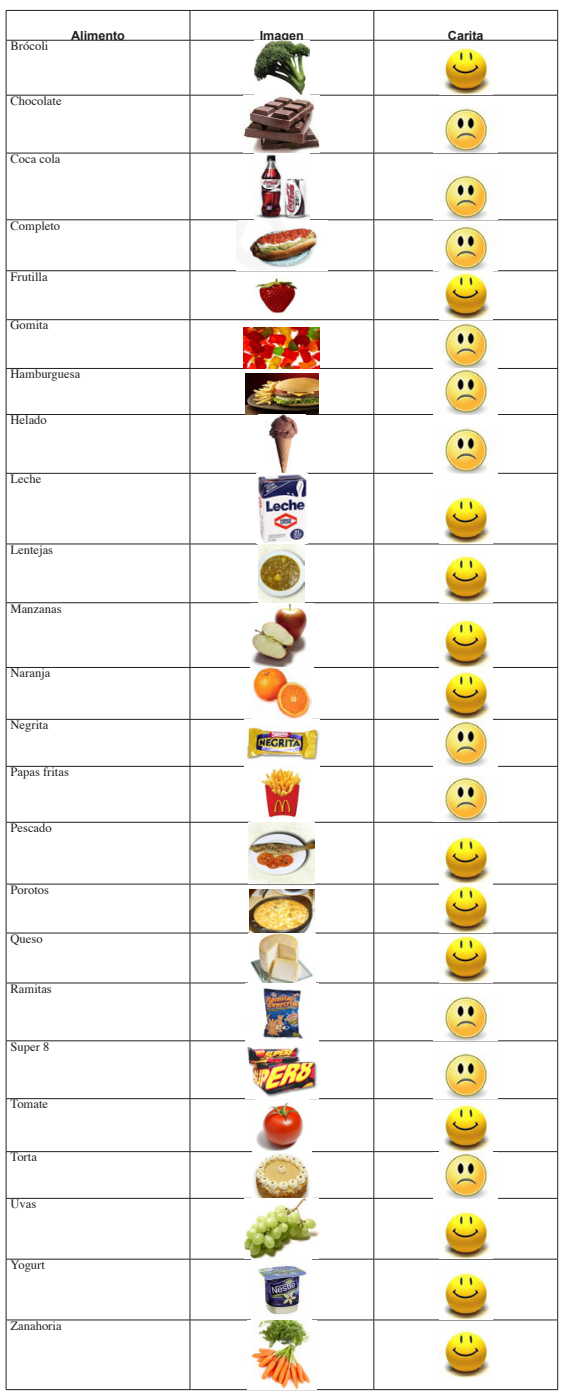


alimentos saludables y de alimentos no saludables, a una -"carita feliz y sana"- si el alimento es -"sano o bueno para el cuerpo".-; o, a una -"carita triste y enferma "- si el alimento es-" no saludable o malo para el cuerpo". En relación, a la "carita feliz" y, a la "carita triste" se determinó usar los términos "carita feliz y sana", y "carita triste y enferma", para evitar confusiones en algunos alumnos que podían asociar el compartir en familia con la comida no sana o chatarra, considerando que el fin de semana, algunas familias realizan como actividad recreativa, el compartir comida chatarra fuera del hogar, tales como productos elaborados altos en grasa saturada, azúcares agregados y sal (hamburguesas, papas fritas, hot dog, snacks dulces y salados entre otros).

Las ilustraciones de los alimentos, el material, el diseño y el tamaño, se determinaron de acuerdo a parámetros establecidos con el grupo de expertos, a los que se sometieron para su elaboración y validación y fueron aplicadas en un grupo de escolares de kinder asistentes al Jardín Infantil de la Universidad de Playa Ancha. El tamaño de las ilustraciones fue de $8 \mathrm{~cm} \times 8 \mathrm{~cm}$ para las actividades grupales y $20 \mathrm{~cm}$ para las actividades individuales. En el diseño, se consideraron los siguientes criterios; i) que las ilustraciones fueran lo más similar al producto natural y a las preparaciones habituales de los productos seleccionados, evitando las caricaturas; ii) que tuvieran la menor distorsión posible respecto al alimento natural, para no producir asociaciones incorrectas; iii) la selección de los alimentos saludables se seleccionaron en base a cinco grupos de alimentos, considerados buena fuente de nutrientes críticos; lácteos; minerales -calcio; pescado, ácidos grasos omega 3; verduras, frutas y legumbres, vitaminas, antioxidantes, y fibra dietaria; iv) las imágenes de alimentos no saludables, se seleccionaron de alimentos ricos en grasas, sal y azúcar; papas fritas, bocadillos, helados, chocolates, bebidas gaseosas, hot dogs y dulces; v) se determinó una escala de cinco puntos, para evaluar el nivel de conocimientos; la escala se elaboró considerando frecuencia de asociación de los alimentos saludables y los no saludables, como se describe en la tabla 2.

El instrumento se aplicó a través de actividades grupales e individuales por nivel escolar. Actividad grupal; i) se conformaron grupos con un máximo de 5 alumnos; ii) a cada grupo curso se les explicó en forma sencilla en que consistía la asociación de alimentos saludables y no saludables con la carita feliz o triste; iii) la carita feliz, se ponía feliz, cuando el alimento hacía bien para el organismo, cumpliendo una función buena para el cuerpo (alimentos saludables); y se ponía triste, cuando el alimento era malo para cuerpo y cumplía una función que lo enfermaba (alimentos no saludables); iv) en la actividad individual, a cada alumno se le mostraba una lámina distinta a las usadas en la actividad grupal, el que debía indicar si era buena o mala para el cuerpo (saludable/no saludable); v) las láminas entregadas por grupo, estaban conformadas por un $50 \%$ de láminas con alimentos saludables y un 50\% de láminas con alimentos no saludables, sin repetición de alimentos.

\section{CONDUCTAS EN ALIMENTACIÓN}

El método consistió en la identificación de los alimentos, que los escolares habitualmente consumen de colación en el colegio, a través de una actividad individual, en donde debían dibujar los alimentos consumidos de colación en una semana de clases. Se definió que las colaciones saludables estaban conformadas por lácteos, frutas, sándwich con queso, quesillo, pescados enlatados y vegetales. Esta actividad, contempló las siguientes etapas; i) a cada escolar se le entregó una hoja de papel en blanco, tamaño oficio dividida en 5 espacios; ii) cada espacio representaba un día de la semana escolar (lunes a viernes); iii) en cada espacio el alumno tenía que dibujar las colaciones que traía de su casa o que compraba si disponía de dinero y la frecuencia de consumo de cada colación dibujada; iv) se determinó que las colaciones eran saludables con habitualidad si el alumno dibujaba 3 o más alimentos saludables durante la semana y que sus colaciones eran no saludables con habitualidad, si dibujaban 3 o mas alimentos no saludables.

\section{TABLA 2}

\section{Escala de evaluación del nivel de conocimiento sobre alimentación saludable}

$<10 \%$ de asociaciones correctas: muy poco conocimiento.

10-30\% de asociaciones correctas: bajo nivel de conocimiento.

30-50\% de asociaciones correctas: nivel de conocimiento medio.

50- 70\% de asociaciones correctas: buen nivel de conocimiento.

$>70 \%$ de asociaciones correctas: elevado nivel de conocimiento. 


\section{ANALISIS ESTADÍSTICO}

Los datos fueron procesados en el programa Microsoft Excel en un estudio descriptivo con las características señaladas anteriormente.

\section{RESULTADOS Y DISCUSIÓN}

Evaluación nutricional. La distribución del estado nutricional por nivel escolar se puede apreciar, en las figuras 1, 2, 3 y 4. En kinder, se observó una mayor prevalencia de sobrepeso respecto al primer año básico, (29,7\% vs24\%); y una menor prevalencia de obesidad $(18,8 \%$ vs $27 \%)$. En las figuras 3 y 4, se observa la distribución del estado nutricional según sexo y nivel escolar. Se observó en kinder una mayor prevalencia de niñas en riesgo de obesidad y obesidad respecto a los niños $(35,7 \%$ vs $25,4 \%)$ y $(19,0 \%$ vs $18,6 \%)$, res-

\section{FIGURA 1}

Estado nutricional de escolares de transición mayor. Valparaíso, 2008
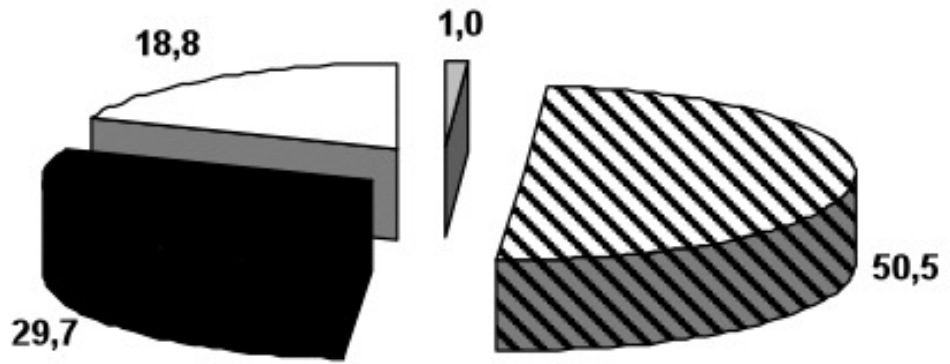

口BAJO PESO $\square$ NORMO PESO $\square$ RIESGO OBESIDAD $\square$ OBESIDAD

\section{FIGURA 2}

Estado nutricional de escolares de primer año básico. Escuelas focalizadas por obesidad. Valparaíso, 2008

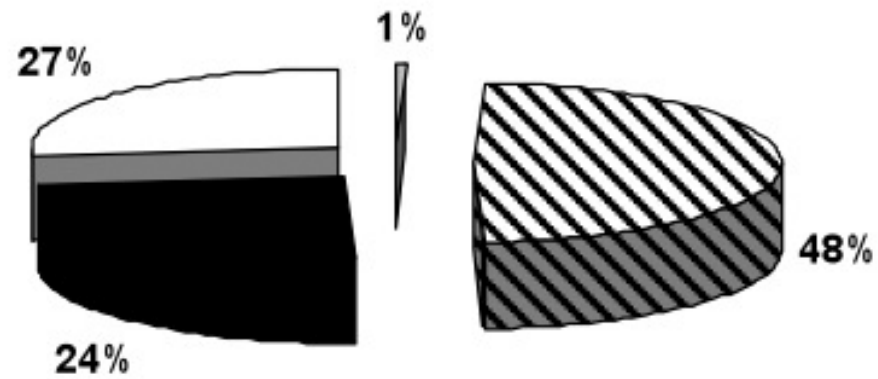

BAJO PESO $\boldsymbol{\Delta}$ NORMO PESO $\boldsymbol{\square}$ RIESGO OBESIDAD $\mathrm{OBBESIDAD}$ 
pectivamente. La prevalencia de sobrepeso fue mayor en el primer año básico (25,0 vs $23,4 \%)$ y $(27,8$ vs $25,5 \%$ ). La malnutrición por exceso afectó a 48,5\% y $51,0 \%$ de los escolares de kinder y primer año básico, respectivamente.

Evaluación de conocimientos. La aplicación del instrumento Caritas, indicó un $77 \%$ y un $87 \%$ de asociaciones correctas para los escolares de kinder y primer año básico, respectivamente. (figuras 5, 6).

Evaluación de conductas. La aplicación del instrumento "Colaciones más habituales" para reconocer el tipo de colaciones saludables y no saludables y la frecuencia de consumo, indicó que un $90 \%$ y un $64 \%$ de los escolares del nivel de kinder y del primer año básico llevaban colaciones saludables tres o más veces a la semana.

\section{FIGURA 3}

Estado nutricional de escolares transición mayor según sexo.

Escuelas focalizadas por obesidad. Valparaíso, 2008

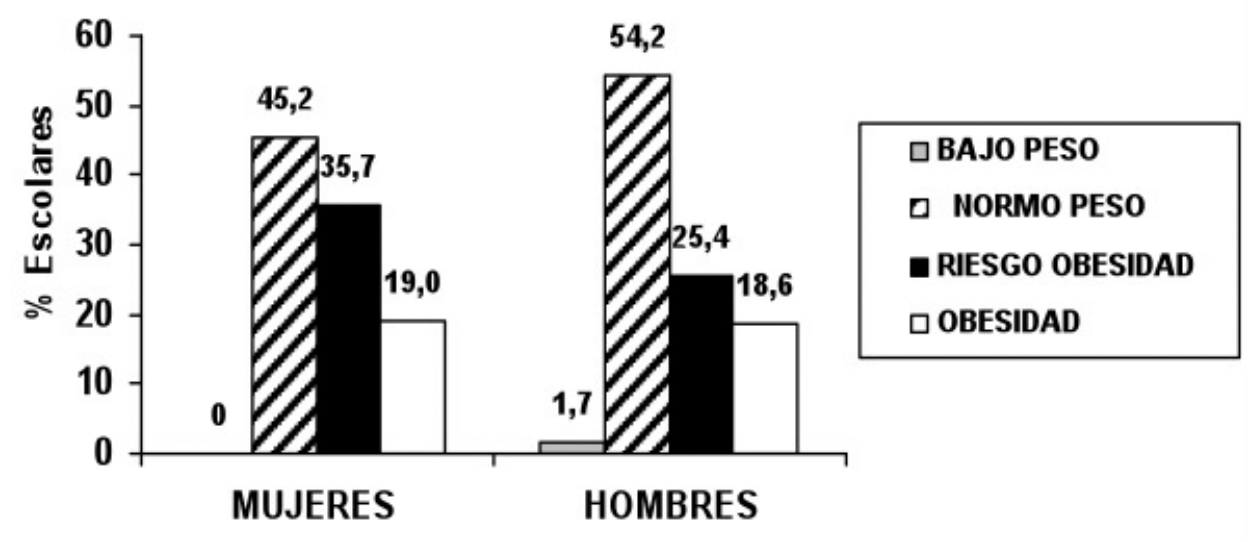

FIGURA 4

Estado nutricional de escolares de primer año básico según sexo. Valparaíso, 2008

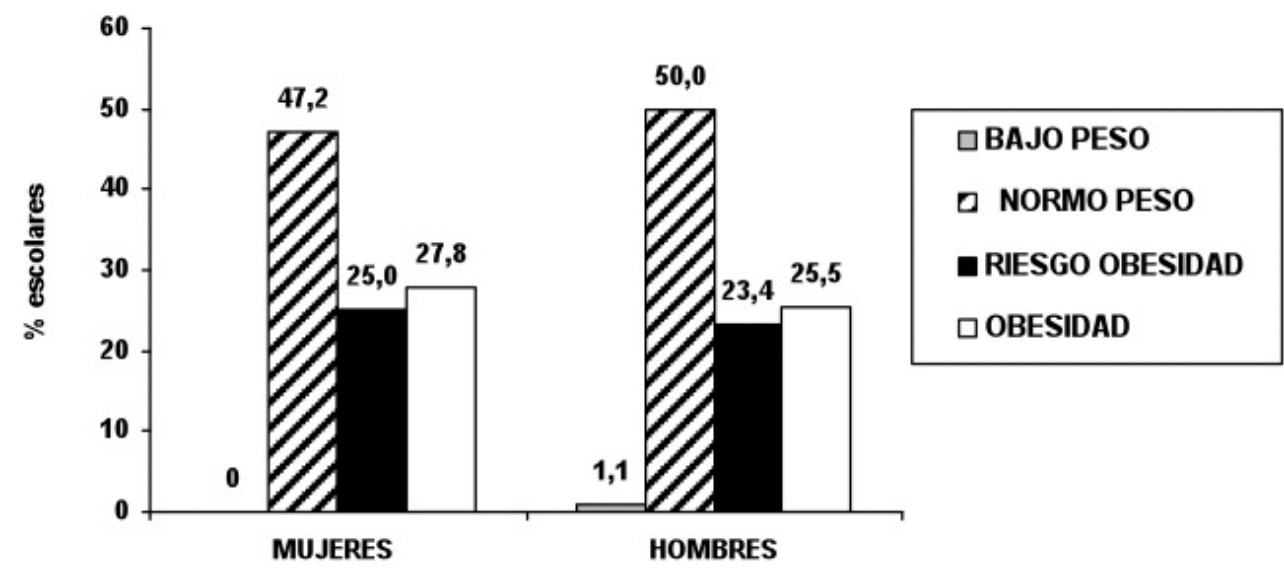




\section{DISCUSIÓN}

Los resultados correspondientes al estado nutricional de los escolares de primer año básico de este estudio, son levemente mayores que el promedio nacional y regional en lo que respecta a malnutrición por exceso, razón por la cual fueron focalizadas en el año 2008, para realizar una intervención en el marco de la EGO. En nuestro país, la prevalencia de obesidad en escolares es alta. En el 2008, las cifras entregadas por el MINSAL respecto a los niños/as del tramo de edad entre 48 a 71 meses, indican que la prevalencia de obesidad es de un $9,4 \%$, experimentando un leve descenso respecto al 2007, que fue de $9,6 \%$. A nivel de la comuna de Valparaíso, la prevalencia alcanzó a un 9,6\% en el año 2008 y un $10,1 \%$ en el 2007 (14). Asimismo, JUNAEB a nivel nacional, indicó que la obesidad experimento un leve

\section{FIGURA 5}

Nivel de conocimientos en alimentación y nutrición. Nivel transición mayor.

Escuelas focalizadas por obesidad. Valparaíso, 2008

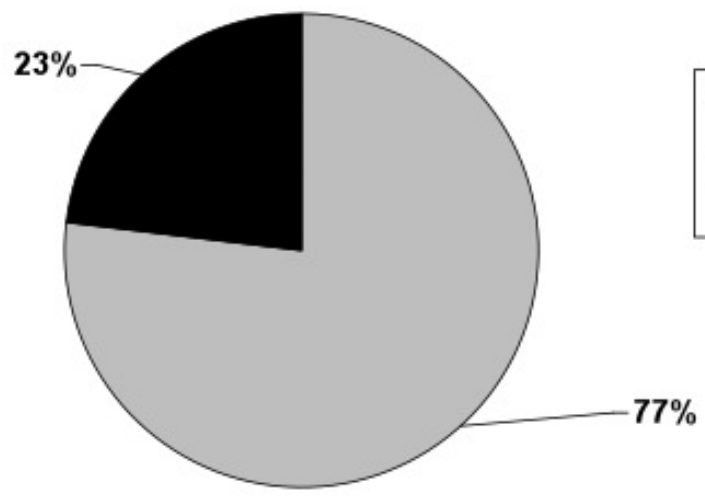

Asociaciones

correctas

Asociaciones

incorrectas

\section{FIGURA 6}

Nivel de conocimientos en alimentación y nutrición. Escuelas focalizadas por obesidad.

Primer año básico. Valparaíso, 2008

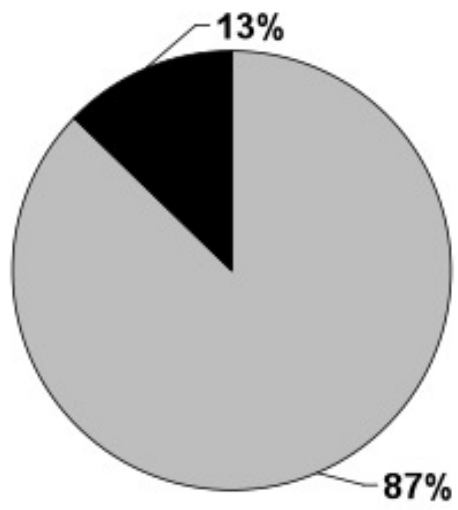

Asociaciones correctas

Asociaciones incorrectas 
descenso en el 2008 respecto al 2007 en los escolares del primer año básico, variando de un $21,4 \%$ a un 20,8\% y de un $21,4 \%$ a un $21,1 \%$ en la V Región. En relación al sobrepeso, a nivel nacional, las cifras se mantuvieron constantes para ambos períodos en un $22,4 \%$; ; por sexo, la prevalencia de obesidad experimenta un leve descenso de $10,6 \%$ a $10.2 \%$ para las niñas y de $11,2 \%$ a $10,5 \%$ para los niños (15).
Este estudio muestra una mayor prevalencia de obesidad en relación a las cifras nacionales y regionales. Se aprecia además que la obesidad es mayor en el primer año básico que en el nivel de transición $(27,0$ vs18, 8\%). Esta situación, se podría interpretar que en la educación preescolar habría un mayor control de la alimentación de parte del sistema escolar sobre los alumnos y que los padres y apoderados responden a las

\section{FIGURA 7}

Conductas alimentarias. Nivel transición mayor.

Escuelas focalizadas por obesidad. Valparaíso, 2008

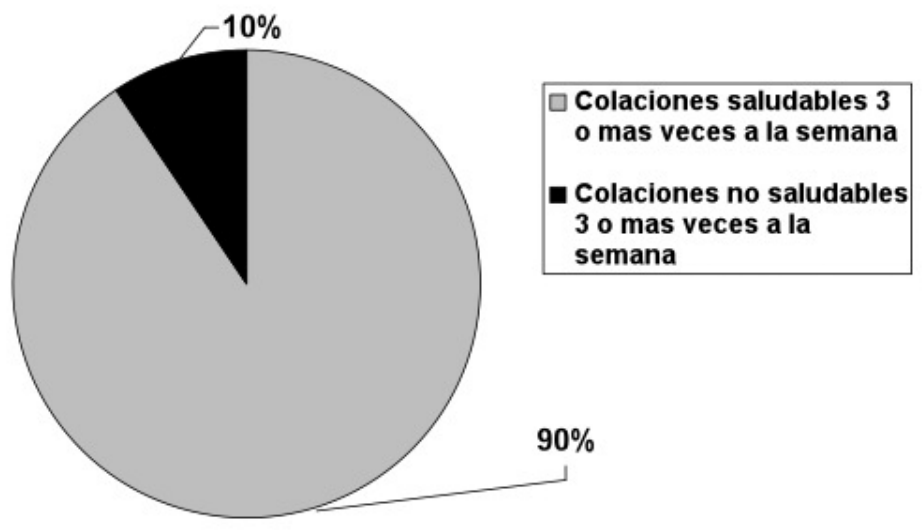

\section{FIGURA 8}

Conductas alimentarias. Primer año básico.

Escuelas focalizadas por obesidad. Valparaíso, 2008

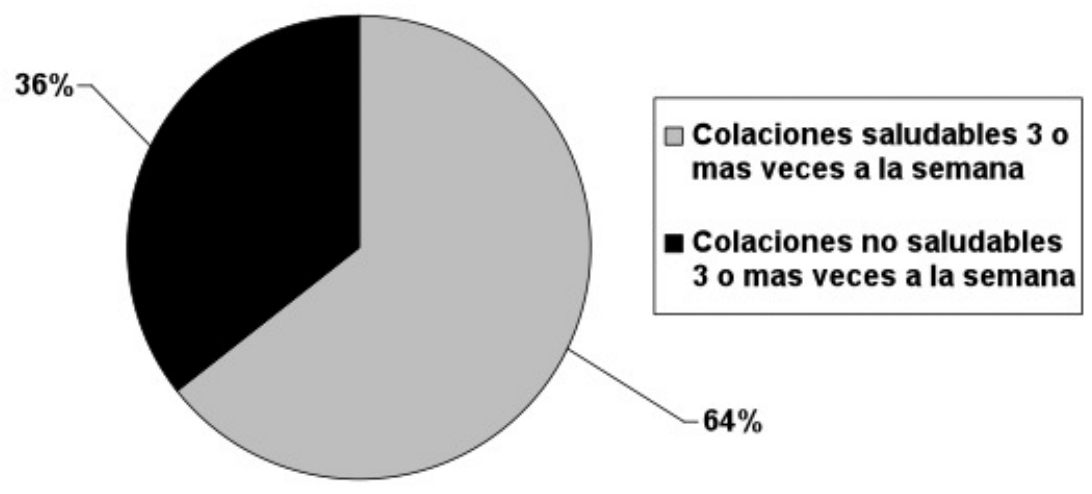


exigencias respecto a la alimentación a entregar a los menores, como es por una parte, la determinación de las colaciones permitidas a llevar por los alumnos y por otra, la ausencia de kioscos escolares o el acceso a estos en este nivel preescolar, lo que no ocurre en la educación básica. Las cifras de sobrepeso y obesidad encontradas y otros estudios realizados en el país $(15,16)$ señalan la importancia de analizar la efectividad de las distintas acciones locales, que se han implementado en promoción de la salud dirigidas a estos grupos de población y con esa base elaborar nuevas estrategias a desarrollar al interior de las escuelas para enfrentar este problema de salud pública, entre otras iniciativas (17 - 20).

Conocimientos en alimentación. Los resultados indican que la mayoría de los alumnos realiza una adecuada asociación de los alimentos saludables y no saludables, y poseen un cierto nivel de conocimientos, de lo que se podría deducir que han recibido información sobre los beneficios de la alimentación sana en la escuela y en sus hogares. Cabe destacar, que se observó que un grupo de alumnos presentó dificultades para explicar el porque de sus respuestas, así como se detectó en otro grupo de escolares de primer año básico que asociaban correctamente el alimento con sus beneficios para el cuerpo, pero en la colación preferían y llevaba alimentos altos en sal, azúcar y grasa saturada, lo que se podría asociar al efecto que la publicidad y los medios de comunicación ejercen en la elección de éstos.

Conductas en alimentación. La conducta alimentaria es el conjunto de acciones que establecen los seres humanos con los alimentos, la que está relacionada con los comportamientos aprendidos en la familia, la imitación de modelos, el status social, los simbolismos afectivos, la disponibilidad y acceso a los alimentos (21 -23). Los resultados señalan, que hay un alto porcentaje de alumnos que consumen colaciones saludables, de lo que se podría deducir que en la escuela y en algunos hogares, los están orientando a optar por este tipo de colaciones, lo que indica según criterio definido, muy buenos hábitos alimentarios en relación a la variable colación escolar en los grupos estudiados.

En relación a conocimientos y conductas en alimentación y nutrición en escolares, se orientan a evaluar la frecuencia de consumo de alimentos considerados de riesgo o protectores de la salud $(16,20,22)$. En los estudios que se basan en métodos de evaluación sensorial, pruebas afectivas (hedónicas) y pruebas de preferencia, se describen preferentemente, los orientados a adultos. Entre estos, se señalan los test de comparación pareada, la escala hedónica y la escala hedónica facial. El término "hedónico" se define como "haciéndolo con placer". En este test, el panelista expresa el grado de gusto o disgusto por medio de escalas. La escala hedónica facial, que se aplica a adultos, es una escala de 5 puntos, que distintos investigadores (24 - 28) han usado para desarrollar una escala hedónica facial para usar en niños y adultos no alfabetizados orientados a evaluar la aceptación o rechazo de alimentos en relación al gusto de los alimentos, cuyo puntaje se determina por la expresión del rostro de agrado o desagrado. En este tipo de estudios, la información obtenida puede ser cuestionable ya que los niños/as pueden estar influenciados por la cara alegre de la figura y no por la función del alimento $(29,30)$.

En la población infantil, la preferencia por uno u otro alimento está determinada por un conjunto complejo de estímulos sensoriales y culturales y no sólo por la predilección por sabores simples, como dulce o salado; este hecho revela que la estructura de las opciones alimentarias depende de bases biológicas, pero también educacionales. Algunos autores han indicado que la medición de la aceptación del alimento por pre-escolares se dificulta por la falta de instrumentos de análisis sensorial adaptado a este grupo de población, que presenta una estructura de percepción sensorial diferente de los adultos $(14,22,25,28)$.

En la elección de los alimentos, los medios de comunicación y la publicidad de éstos tienen una gran influencia al momento de escoger lo que se consume, ejerciendo un rol decisivo por sobre los conocimientos de las características saludables o no de los alimentos. Por ello, el rol de la familia es fundamental para desarrollar hábitos y conductas saludables; el problema es que los hábitos y conductas de los padres, también se ven influenciadas por los medios de comunicación y la publicidad (34). El sobrepeso y la obesidad están determinados también por factores relativos a los padres y al ambiente familiar. En el desarrollo de hábitos saludables y cambios en la alimentación y nutrición de los niños, el rol de los padres y el estilo de vida de la familia serán decisivos para enfrentar la epidemia de la obesidad, los niños imitan lo que ven de sus padres, por lo cual, los conocimientos y conductas de los padres es fundamental para la elaboración de los patrones alimentarios de los hijos.

En esta área hay aspectos que deben ser objetos de otros estudios y elaborar instrumentos que permitan obtener información sobre las variables que influyen en los conocimientos, conductas, hábitos y preferencias alimentarias de la población escolar, especialmente a temprana edad.

Los resultados de este estudio indican la importancia de controlar a los escolares de kinder y primer año básico respectivamente, los cuales están a tiempo de modificar sus hábitos, conductas y estado nutricional y evitar los 
problemas de la malnutrición por exceso (31 - 33).

Respecto a los principales facilitadores y obstaculizadores para ejecutar las acciones de promoción de la salud en las escuelas focalizadas por obesidad, se identificaron como facilitadores los siguientes aspectos i) Funcionamiento y liderazgo del Vida Chile de Valparaíso ii) Trabajo intersectorial de los participantes en mesa comunal y apoyo de los nutricionistas de los consultorios iii) rol de la Universidad en el desarrollo de las políticas regionales a través de apoyos específicos en el área de alimentación y nutrición iv) evaluación positiva por la mayoría de los directivos y profesores de las Escuelas de estas acciones. En obstaculizadores, se identificaron i): el atraso en la información hacia el nivel local de la planificación de las acciones programadas desde el nivel central (MINSAL), lo que dificulta la coordinación oportuna y anticipada con el sector educación que altera la programación de las actividades curriculares en las escuelas, lo que genera un menor apoyo de algunos directivos para su realización; (educación planifica y organiza sus actividades curriculares en noviembre- diciembre del año anterior y salud comienza a planificar las acciones entre marzo y abril y las ejecuta en mayo-junio del año en curso) ; iii) presión desde el nivel central por el cumplimiento de la programación anual, lo que impide realizar acciones de mediano y largo plazo; iv) ausencia de recursos humanos especializados en nutrición y alimentación al interior de las escuelas para realizar en forma continua, permanente y sostenida vigilancia alimentaria y nutricional de las actividades que se realizan en la comunidad escolar, entre otras.

\section{CONCLUSIONES}

Estado nutricional, conductas y conocimientos. 1) En Chile, la malnutrición por exceso en los escolares en edad temprana es un problema de salud pública. Se dispone de suficiente información sobre los afectados, la dimensión y severidad del problema de malnutrición por exceso. 2) Se han implementado diversas estrategias a nivel público y privado relacionadas con la promoción de la salud sin lograr el impacto deseado. 3) Los resultados de este estudio y otros indican que existe un cierto nivel de conocimientos en los escolares del nivel de kinder y primer año básico, sobre los alimentos saludables y no saludables, pero que los comportamientos y conductas frente a la elección de los alimentos no refleja los conocimientos que se poseen. 4) A nivel de kinder, el Jardín Infantil contribuiría a la promoción de conductas saludables en los alumnos y padres, ejerciendo una acción protectora a través de la planificación diaria de la colación que los padres deben seleccionar y enviar al jardín infantil y la ausencia de kioscos al interior de los recintos; 5) la pérdida de esta acción protectora que ejerce el jardín infantil al ingreso de los alumnos al ciclo básico, estaría reflejada en el aumento en la elección de alimentos no saludables que los alumnos llevan o compran para la colación escolar. 6) Lo anterior, señala que se requiere avanzar en reunir información sobre conocimientos, actitudes y comportamientos en alimentación y nutrición de los escolares en distintos niveles, reforzar los conocimientos que existen en los padres y entregar capacitaciones permanentes a la familia sobre el rol protector de la salud de una alimentación saludable. 6) Alertar a la comunidad sobre el efecto de la publicidad y los medios de comunicación sobre la elección de los alimentos (35). 7) Se deben realizar esfuerzos para lograr una planificación anticipada de las acciones que el sector salud desarrolla al interior de las escuelas, para lograr un mayor impacto de las intervenciones que ejecuta en el ámbito de la promoción de la salud, para lograr los impactos esperados con los esfuerzos invertidos.

\section{RESUMEN}

En el 2008, en el marco del Plan Nacional de Promoción de la Salud y del Plan Comunal de Promoción de la Salud se priorizan acciones para abordar la obesidad escolar interviniendo con la Estrategia Global contra la Obesidad las escuelas con los más altos índices de obesidad a nivel comunal, focalizando en escolares de kinder (escolares entre 5-6 años de edad) y primer año básico (escolares entre 6-7 años de edad). En Valparaíso, se evaluaron las acciones del Plan Comunal de Promoción de la Salud en 3 de las 4 Escuelas seleccionadas. Los objetivos de esta intervención fueron; 1) evaluar el estado nutricional de los niños/niñas de los niveles participantes; 2) recopilar antecedentes sobre conocimientos y conductas asociadas a la alimentación y nutrición y estilos de vida en los escolares de kinder y primer año básico y 3) identificar dificultades y fortalezas que enfrentan la implementación de las políticas sanitarias a nivel local. Se realizó un estudio descriptivo, diseño no experimental, muestra intencionada no aleatoria. $\mathrm{La}$ muestra incluyó a 267 escolares. Resultados; se detectó $18,8 \%$ obesidad en el nivel de transición mayor y $27 \%$ en el primer año básico evaluados según Normas Técnicas del Ministerio de Salud de Chile (MINSAL) en base a la referencia de la OMS 2006; para evaluar conocimientos y conductas los autores elaboraron y aplicaron los instrumentos "Caritas" y "Colaciones más saludables". Se observó un $77 \%$ y $87 \%$; y $90 \%$ y $64 \%$ de asociaciones correctas para conocimientos y conductas, respectivamente. Facilitadores; trabajo intersectorial y valoración desde educación; obstaculizadores; acciones desfasadas que alteran la planificación curricular de las 
escuelas. Las cifras de malnutrición por exceso y la dificultad para revertir esta realidad, requiere avanzar en identificar conocimientos y conductas alimentarias nutricionales en la población.

Palabras clave: Escuelas promotoras de la salud, conocimientos y conductas en alimentación, obesidad infantil, promoción de la salud.

Dirigir la correspondencia a:

Profesora

Mirta Crovetto M

Subida Carvallo 290

Playa Ancha

Valparaíso- Chile

Fono 56-32 -2500541

E-mail: mcrovetto@upla.cl

Agradecimientos: A los equipos de promoción de la salud, nutricionistas de los consultorios Padre Damián, Esperanza y Barón y a Lía Godoy Alarcón, María José González Rojas, Nicole Rivas Meneses en representación de las/os alumnas/os de 4to año de la Carrera de Nutrición y Dietética, de la Universidad de Playa Ancha.

\section{BIBLIOGRAFÍA}

1. Ministerio de Salud. División atención primaria. Unidad de Promoción de la Salud. Promoción de la salud para Chile: plan nacional de promoción de la salud. Santiago, Chile. 1999, p 204.

2. Ministerio de Salud. Objetivos Sanitarios para la década 2000-2010. En: El Vigía: Boletín de Vigilancia en Salud Pública de Chile, 20025, $\mathrm{N}^{\circ} 15$ Disponibleen: http://epi.minsal.cl/epi/html/elvigia/ vigia15.pdf

3. Organización Mundial para la Salud (OPS/OMS). Escuelas Promotoras de Salud: entornos saludables y mejor salud para las generaciones futuras. 1998 Washington, DC, USA.

4. Organización Mundial para la Salud. Educación para la Salud en el Ámbito Escolar: Una perspectiva integral y guía para la acción basada en la experiencia latinoamericana. Serie HSS/SILOS-37 2004. Washington, DC, OPS/OMS.

5. Organización Mundial para la Salud. Escuelas Promotoras de la Salud: La Experiencia Centroamericana. Serie Promoción de la Salud No 12003. Washington, DC, OPS/OMS.

6. Junta Nacional de Auxilio Escolar y Becas (JUNAEB). Escuelas promotoras de salud para el aprendizaje. Escuelas Saludables_Disponible en. hth://www.junaeb.cl/salud/escuelas_saludables. htm. [Consultado el 20 de diciembre de 2007
7. Junta Nacional de Auxilio Escolar y Becas (JUNAEB). Situación nutricional de los escolares chilenos de $1^{\circ}$ Básico. Santiago, Chile: JUNAEB. Disponible en: http://sistemas.junaeb.cl/ estadosnutricionales_2008/index2.php [consultado el 4 noviembre 2009]

8. Gobierno de Chile. Ministerio de Salud. Estrategia Global contra la Obesidad (EGO-Chile). Documento de Trabajo. 2005 Disponible en: http://www.egochile.cl/paginas/ego.htm

9. Corporación Municipal Valparaíso_Plan de Salud Comunal 2009 Disponibleen http./Www.cmvalpo. cl/documentos/PSCValpo2009.pdf

10. Ministerio de Salud Informe de la situación nutri cionalen el país 2006-2008_ Disponible en http./ www redsalud gov cl/portal/url/item/6b4d0a9b5cb 42e14e04001011e01277c.pdf

11. Gobierno de Chile. Ministerio de Salud. Norma Técnica de Evaluación Nutricionaldel niño de 6a 18 años (2003) Disponibleen http./ / www redsalud govel/archivos/alimentosynutricion/estrategiaintervencion/NormaEvNut6a18anos.pdf

12. Vera-Villarroel P, Bastías A, Mena L. Construcción de una escala de creencias de obesidad en niños (ECOI) Rev Mex Psicol. 2004; 21(2):191-202.

13. Almeida TC, Hough G, Damásio MH, da Silva MAAP. Avanços em análise sensorial. São Paulo, Ed. Varela, 1999.

14. Wardle J, Sanderson S, Leigh Gibson E, Rapoport L. Factor-anlytic structure of food preferente in touryear-old children en UK. Appetite 2001; 37:217-23.

15. Loaiza S. Taibo M. Cornejo A. y Atalah E. Evolución del estado nutricional en una cohorte de escolares chilenos: ¿Un cambio real o ficticio? Rev Med Chile 137:11·1449-1456 Disponibleen h htp./1www scielo cl/scielo php?script=sci_arttext\&pid=S0034$98872009001100006 \& \operatorname{lng}=$ es\&nrm=iso [Consultado 4 noviembre 2009]

16. Macmillan, N. Evaluación del estado nutricional, hábitos de alimentación y actividad física en escolares de $1^{\circ}$ básico de Isla de Pascua. Rev Chil Nutr. 2005; 32: 232-237

17. Olivares S. Morón C. Zacarías I. Andrade M. Lera L. Díaz N. Vio F. Propuesta metodológica para incorporar la educación en nutrición en la enseñanza básica: la experiencia chilena. Arch Latin Nutr 2004; 54(Sup1): 33-9.

18. Olivares S, Cortez S, Bustos N, González D, Zacarías I, Figueroa P. Crecer en forma: el poder del movimiento y la alimentación. Santiago 2006; INTA, Universidad de Chile.

19. Uauy R, Kain J. The epidemiological transition: 
need to incorporate obesity prevention into nutrition programmes. Pub Health Nutr. 2001;15:47.

20. Kain J. Uauy R. Leyton B. Cerda R. Olivares S. Vio F. Efectividad de una intervención en educación alimentaria y actividad física para prevenir obesidad en escolares de la ciudad de Casablanca, Chile (2003-2004). Rev Med Chil. 2008; 136:22-30.

21. Olivares S. Bustos N. Moreno X. Lera L. Cortés S. Actitudes y prácticas sobre alimentación y actividad física en niños obesos y sus madres en Santiago, Chile. Rev Chil Nutr 2006 33(2): 170-9.

22. Olivares S. Yañez R. Díaz N. Publicidad de Alimentos y Conductas alimentarias en Escolares de $5^{\circ}$ a $8^{\circ}$ básico. Rev. Chil. Nutr., 2003; 30 (1): 36-42.

23. Weisstaub G, Castillo C. Desarrollo de la conducta alimentaria en la infancia y sus alteraciones. Rev Chil Nutr. 2002; 29(3): 280-285.

24. Meilgaard, M. C., Civille, G. V. and Carr, B. T. "Sensory Evaluation Techniques" CRC Press, Inc., Boca Raton, Fl USA. 1991.

25. Fuentes A. Aporte de la psicología y sociología a la Promoción de la Salud en Chile. Cuad Med Soc. 2008; 48:118-124.

26. Bergara-Almeida S. Aparecida M. Da Silva A.P. Hedonic scale with reference : performance in obtaining predictive models. Food Quality Preference, 2002; 13 (1):57-64.

27. Sparkman Af. Simmons Lf. Sullivan S. RobertsGray C. Tools to measure sensory appeal of menus planned for children. J Am Diet Assoc 1998; 88:488491.

28. Sánchez J. Botto E. Del Canto F. Introducción al análisis sensorial de los alimentos. México DF., Editorial Alfaomega. 2002.

29. Anzaldua A. La evaluación sensorial de los alimentos: en la teoría y la práctica. Zaragoza, Acribia. 1994.

30. Wardle J. Sanderson S. Leigh Gibson E. Rapoport L. Factor-analytic structure of food preferences in four-year-old children in the UK. Appetite 2001; 37:217-23.

31. Hursti U. Changing food habits in children and adolescents. Experiences from intervention studies. Au Scand Jr Nutr. 1998; 42:39-41.

32. Alvares D, Semíramis M. Zapico J. y De aguiar carrazedo J. Adaptación de la escala hedónica facial para medir preferencias alimentarias de alumnos de pre-escolar. Rev. Chil. Nutr. 2008; 35: 38-42. Disponible en: http://www.scielo.cl/scielo. php?pid=S0717-75182008000100005\&script $=$ sci_ arttext [Consultado 06-01- 2010].

33. Contento I. Balch, G. Bronner Y. Paige D. Gross S. Bisignani L. Lytle L. Maloney S. Olson C. y Sharaga, S. The effectiveness of nutrition education and implications for nutrition education policy, programs and research. A review of research. J Nutr Educ. 1995; 27: 284-380.

34. Organización Mundial para la Salud. Marketing of Food and Nonalcoholic Beverages to Children, Report of a WHO Forum an Technical Meeting , Oslo, 2-5 May, 2006.

35. Girardi G. Proyecto de ley sobre regulación de alimentos pen saludables 2009 Dispopible en: http://sil.congreso.cl/docsil/proy5308.doc 